J. Clin. Chem. Clin. Biochem.

Vol. 24, 1986, pp. 735-740

(C) 1986 Walter de Gruyter \& Co.

Berlin - New York

\title{
Immunoturbidimetric Measurement of Transferrin
}

\author{
By B. A. Dilena and M.J. Peake
}

Department of Biochemistry and Chemical Pathology, Flinders Medical Centre, Bedford Park, South Australia 5042, Australia

(Received January 13/May 15, 1986)

Summary: This paper describes the development of an automated immunoturbidimetric assay for transferrin on a centrifugal analyser. Regression analysis of transferrin values measured immunoturbidimetrically demonstrates good agreement with data obtained by radial immunodiffusion $(\mathrm{y}=0.997+0.024 \mathrm{~g} / \mathrm{l}, \mathrm{r}=0.980$, $\mathrm{n}=50)$. The assay has a detection limit of $1.0 \mathrm{~g} / 1$ and working range of approximately 1.0 to $6.0 \mathrm{~g} / \mathrm{l}$ of transferrin. Day-to-day coefficient of variation is less than $3.5 \%$. Immunoturbidimetric transferrin $(\mathrm{g} / \mathrm{l})$ and total iron binding capacity values $(\mu \mathrm{mol} / \mathrm{l})$ were compared using an established total iron binding capacity method $(\mathrm{y}=0.050 \mathrm{x}-0.030 \mathrm{~g} / \mathrm{l}, \mathrm{r}=0.967, \mathrm{n}=50)$. Minimal interference was found for lipaemic, haemolysed or icteric samples. Transferrin reference values with a mean of $3.05 \mathrm{~g} / 1$ and $95 \%$ limits from 2.45 to $3.65 \mathrm{~g} / 1$ were derived using serum from 300 apparently healthy subjects (150 males, 150 females). We conclude that the proposed transferrin method is more reliable and easier to perform than presently available total iron binding capacity methods.

\section{Immunturbidimetrische Bestimmung von Transferrin}

Zusammenfassung: Wir beschreiben eine immunturbidimetrische Methode zur Bestimmung von Transferrin an einem Zentrifugalanalysator. Die Regressionsanalyse der immunturbidimetrisch gemessenen Transferrinwerte zeigt gute Übereinstimmung mit Ergebnissen der radialen Immundiffusion $(y=0,997 \mathrm{x}+0,024 \mathrm{~g} / \mathrm{l}$, $\mathrm{r}=0,980, \mathrm{n}=50$ ). Die Methode hat eine Nachweisgrenze von $1,0 \mathrm{~g} / \mathrm{l}$ und einen Arbeitsbereich von $1-6 \mathrm{~g} / \mathrm{l}$ Transferrin. Der Variationskoeffizient von Tag zu Tag ist kleiner als 3,5\%. Immunturbidimetrisch bestimmtes Transferrin $(\mathrm{g} / \mathrm{l})$ und gesamte Eisenbindungskapazität $(\mu \mathrm{mol} / \mathrm{l})$ wurden verglichen: $\mathrm{y}=0,050 \mathrm{x}-0,030 \mathrm{~g} / \mathrm{l}$, $\mathrm{r}=0,967, \mathrm{n}=50$ ). Für lipämische, hämolytische oder ikterische Probẹn wurden minimalen Störungen beobachtet. Im Serum vọn 300 offensichtlich gesunden Personen (150 Männer, 150 Frauen) wurden Referenzwerte ermittelt: $\overline{\mathrm{x}}=3,05 \mathrm{~g} / \mathrm{l} ; 95 \%$-Bereich 2,45-3,65 g/l. Wir schließen, daß die vorgestellte Transferrinmethode zuverlässiger und leichter durchführbar ist als gegenwärtig vorhandene Methoden zur Bestimmung der gesamten Eisenbindungskapapazität.

\section{Introduction}

In recent years, very reliable methods have been developed for the measurement of serum iron. The measurement of total iron binding capacity however, still presents many problems to the clinical biochemist, and this is evidenced by poor precision and accuracy in quality assurance programmes $(1,2)$. In our own laboratory, long-term performance of both chemical (3) and radiometric methods (4) for measuring total iron binding capacity has been disappointing in all but the hands of our most experienced staff.

Transferrin, the main serum iron binding protein (5), has been measured by some laboratories as an alternative to total iron binding capacity in order to eliminate technical problems associated with the saturation of transferrin and removal of excess iron (6). 
We investigated the use of a centrifugal analyser for measuring transferrin immunoturbidimetrically using a recently released software option for processing non-linear standard curves. We report our attempts to establish a more reliable and less time-consuming substitute for total iron binding capacity assays.

\section{Materials and Methods}

Initial procedure

Transferrin was measured on Cobas Bio (Hoffmann-La Roche, Basel, Switzerland) using an immunological transferrin procedure as recommended (Boehringer Mannheim GmbH Cat. No. 661040 - Tab. 1). Patient specimens, quality control materials, and a set of 5 transferrin standards (Boehringer, Cat. No. 475785) were carefully diluted 1 in 11 prior to analysis by mixing $100 \mu \mathrm{l}$ of sample with $1 \mathrm{ml}$ of $9 \mathrm{~g} / 1 \mathrm{NaCl}$ using a Brand Diluette model DL 2/0.1 (Rudolf Brand, Wertheim, W. Germany). Diluted standards were reused for convenience and economy and were stable for 2 weeks at $4^{\circ} \mathrm{C}$. Fibrin deposition in patient samples was avoided by using serum instead of plasma.

\section{Modified iprocedure}

Four modifications were made to improve precision.

1. Anti-transferrin was added as a "start" reagent to samples pre-incubated with buffer in Cobas Bio instead of the recommended simultaneous addition of sample and anti-transferrin. The anti-transferrin was dissolved in $2 \mathrm{ml}$ of buffer rather than $10 \mathrm{ml}$ for use as a "start reagent" and one fifth the volume was used for each assay (tab. 1).

2. Pre-dilution was changed from 1 in 11 to 1 in 21 (100 $\mu$ l of sample $+2.0 \mathrm{ml}$ of $9 \mathrm{~g} / 1 \mathrm{NaCl}$ ) to provide a bigger reserve of diluted standards.

3. Cobas Bio sample volume was increased from $5 \mu \mathrm{l}$ to $15 \mu \mathrm{l}$ to compensate for the change in sample pre-dilution and to generate more reliable absorbance changes for low concentrations of transferrin.

4. An additional standard with a transferrin concentration approximating the mid-point of the reference range was prepared from a $50: 50$ mixture of pre-diluted Boehringer standards 2 and 4 . The Cobas Bio log-logit standard curve was then defined using the maximum number of 6 standards.

\section{Comparative methods}

A radial immunodiffusion method (Behring NOR Partigen Plate OUCK 02/03) was used as a comparative method for transferrin. Fifty patient samples were analysed by both methods. A total iron binding capacity method (7) involving the measurement of the iron concentration (Roche Product No. 0710598) of iron-saturated serum from which excess iron had been removed by magnesium carbonate (Roche Product No. 0710075) was used for comparing total iron binding capacity and immunoturbidimetric transferrin concentrations on an additional 50 serum samples. Total iron binding capacity measurements were also performed using Cobas Bio.

\section{Précision studies}

Within run and day-to-day precision was monitored using Omega 1 and 2 quality control materials (Hyland Diagnostics, Illinois, U.S. A.). These were diluted with each batch of serum samples prior to analysis on Cobas Bio.
Tab. 1. Cobas Bio Centrifugal Analyser settings for the assay of transferrin

\begin{tabular}{lcc}
\hline Parameter & $\begin{array}{l}\text { Initial } \\
\text { settings }\end{array}$ & $\begin{array}{c}\text { Modified } \\
\text { settings }\end{array}$ \\
\hline 1. Units & $\mathrm{g} / \mathrm{l}$ & $\mathrm{g} / \mathrm{l}$ \\
2. Calculation factor & 1000 & 1000 \\
3. Standard 1 conc & 1.13 & 1.13 \\
Standard 2 conc & 1.97 & 1.97 \\
Standard 3 conc & 3.36 & 2.67 \\
Standard 4 conc & 4.78 & 3.36 \\
Standard 5 conc & 6.08 & 4.7 .8 \\
Standard 6 conc & 0.00 & 6.08 \\
6. Limit & 0 & 0 \\
7. Temperature, ${ }^{\circ} \mathrm{C}$ & 25 & 25 \\
8. Type of analysis & 7.5 & 7.6 \\
9. Wavelength, nm & 340 & 340 \\
10. Sample volume, $\mu l$ & $\left.5^{\mathrm{a}}\right)$ & $\left.15^{\mathrm{b}}\right)$ \\
11. Diluent volume, $\mu \mathrm{l}$ & 60 & 60 \\
12. Reagent volume, $\mu \mathrm{l}$ & $\left.250^{\mathrm{c}}\right)$ & $\left.200^{\mathrm{d}}\right)$ \\
13. Incubation time, $\mathrm{s}$ & 0 & 60 \\
14. Start reagent volume, $\mu \mathrm{l}$ & 0 & $\left.50^{\mathrm{c}}\right)$ \\
15. First reading, $\mathrm{s}$ & 5 & 5 \\
16. Time interval, s & 240 & 10 \\
17. No. of readings & 2 & 25 \\
18. Blanking mode & 1 & 1 \\
19. Printout mode & 1 & 1 \\
\hline
\end{tabular}

a) Sample pre-diluted 1 in 11

b) Sample pre-diluted 1 in 21

c) Buffered anti-transferrin (anti-serum dissolved in $10 \mathrm{ml}$ of buffer)

d) Buffer without anti-transferrin

e) Buffered anti-serum (anti-serum dissolved in $2 \mathrm{ml}$ of buffer).

\section{Reference values}

Fifty blood specimens were collected from both males and females in age groups $20 \rightarrow 39,40 \rightarrow 59$, and over 60 years. In total, 300 specimens were collected from apparently healthy individuals with haemoglobin $>1.86 \mathrm{mmol} / \mathrm{l}$ (males) and 1.78 $\mathrm{mmol} / \mathrm{l}$ (females). Transferrin reference values with $95 \%$ limits were established using the parametric Hoffman procedure (8). A non-parametric classification by age and sex was also derived (9).

\section{Results and Discussion}

\section{Method development}

Initial attempts to analyse transferrin on Cobas Bio as recommended by Boehringer were unsuccessful. Within-run imprecision was often greater than $5 \%$ and it was not unusual to obtain individual results more than $20 \%$ lower than expected. Falsely low results were invariably accompanied by falsely high initial absorbance readings 5 seconds after mixing sample with buffered antiserum. It was impossible to completely eliminate this problem, even when initial absorbance measurements were delayed as long as 15 seconds, and by this time the reaction had progressed significantly. The mixing cycle was checked by a Roche engineer and found to be performing to specifications, and the same problem was reproduced on 
Tab. 2. Precision studies for the immunoturbidimetric transferrin assay.

\begin{tabular}{llll}
\hline Sample & $\begin{array}{l}\text { Mean } \\
(\mathrm{g} / \mathrm{l})\end{array}$ & $\begin{array}{l}\text { SD } \\
(\mathrm{g} / \mathrm{l})\end{array}$ & $\begin{array}{l}\mathrm{CV} \\
(\%)\end{array}$ \\
\hline Within-run $\left.^{\mathrm{a}}\right)$ & & & \\
Omega I & $2.134,2.146$ & $0.045,0.039$ & $2.10,1.81$ \\
Omega II & $2.981,2.975$ & $0.012,0.015$ & $0.41,0.52$ \\
Day-to-dayb) & & & \\
Omega I & 2.129 & 0.064 & 3.01 \\
Omega II & 2.896 & 0.100 & 3.45 \\
\hline
\end{tabular}

a) Within-run precision measured in consecutive runs. 28 aliquots of each QC material were analysed per run.

b) Day-to-day precision over the first 5 months of routine use. 81 analyses of each QC material were performed.

another instrument. We therefore decided to quantitate transferrin using a mode of analysis that enabled anti-transferrin to be added as a "start" reagent to samples which had been pre-mixed with buffer during an incubation phase. It was then possible to make a reliable sample blank absorbance measurement as well as monitor the complete reaction absorbance change. Precision improved substantially to that of conventional spectrophotometric assays and withinrotor CV was often less than $1 \%$ (tab. 2). Other modifications were then introduced to further improve the assay.

When the amount of sample added to the antiserum was increased by approximately $50 \%$, better precision

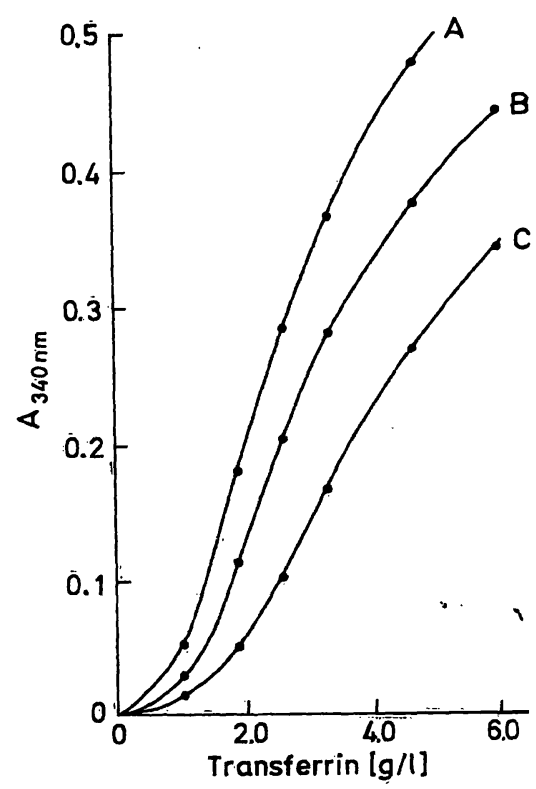

Fig. 1. Transferrin standard curves:
A. Sample volume $=15 \mu$, pre-dilution $=1$ in 21 , reaction time $=10 \mathrm{~min}$
B. Sample volume $=15 \mu$, pre-dilution $=1$ in 21 , reaction time $=4 \mathrm{~min}$
C. Sample volume $=5 \mu \mathrm{l}$, pre-dilution $=1$ in 11 , reaction time $=4 \mathrm{~min}$

was obtained for both patient samples and standard curves. More consistent standard curves were also generated from run to run, and absorbance change doubled for low concentrations of transferrin where good precision is most difficult to obtain (fig. 1). The reliability of the calibration procedure was further improved by using 6 standards instead of 5. With these modifications, fewer iterations were needed to derive a log-logit standard curve, and individual standards showed very little deviation about the line of best fit. It was found that low concentration standards react with anti-transferrin much more slowly than the high concentration standards, and only the latter near end-point after a four minute reaction period. A comparison between standard curves obtained at four minutes and ten minutes is shown in figure 1 . The two lowest standards reach only $50 \%$ and $75 \%$ of the ten minute absorbance after four minutes, in comparison with $85 \%$ by the higher standards. We elected to use a four minute reaction period to reduce analysis time, although longer times or less sample pre-dilution may be more appropriate when analysing mainly low concentration samples.

Immunoturbidimetric and radial immunodiffusion transferrin comparisons

The accuracy of the immunoturbidimetric transferrin assay was assessed by assaying 50 patient sera in duplicate by this method and also by a radial immunodiffusion method. Results are shown in figure 2.

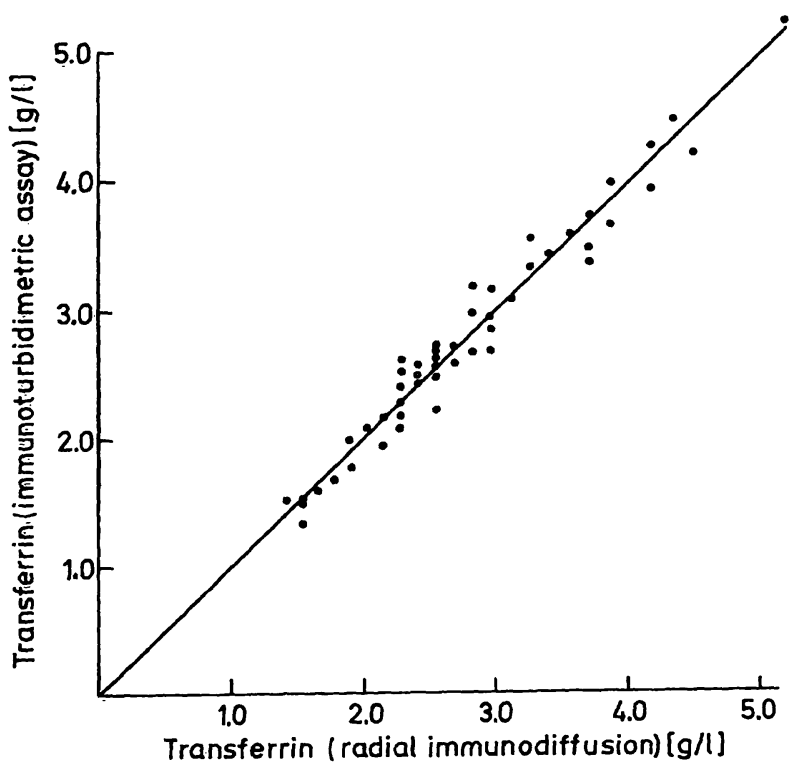

Fig. 2. Comparison of patient specimens analysed for transferrin using an immunoturbidimetric method on Cobas Bio and a radial immunodiffusion method.

$\mathrm{y}$ intercept $=0.024$

slope $=0.997$

$\mathrm{r} \quad=0.980$

n $\quad=50$

$\mathrm{s}_{\mathrm{y} . \mathrm{x}} \quad=0.169$ 
The following relationship between methods was established (concentrations in $\mathrm{g} / \mathrm{l}$ ):

Immunoturbidimetric transferrin $=(0.997 \mathrm{x}$ radial immunodiffusion) $+0.024, \mathrm{r}=0.980, \mathrm{~s}_{\mathrm{y} . \mathrm{x}}=0.169$.

Good agreement was found between individual results and no significant differences were found for visibly lipaemic, icteric or haemolysed samples.

\section{Interference studies}

Interference from haemoglobin and bilirubin was assessed by adding $100 \mu$ lof concentrated solutions of haemolysate and bilirubin (Sigma $98+\%$, catalogue number B 4126) to $10 \mathrm{ml}$ aliquots of a serum pool with an undetectable concentration of haemoglobin and a low concentration of bilirubin $(<10 \mu \mathrm{mol} / \mathrm{l})$. The serum pool was then adjusted with saline in the same ratio. Each sample was analysed in quadruplicate in the same run. No interference was detected from haemoglobin or bilirubin up to the highest concentrations of each substance tested, namely bilirubin, $600 \mu \mathrm{mol} / 1$ and haemoglobin, $43 \mu \mathrm{mol} / 1$ (appearance of gross haemolysis). Even at these concentrations of haemoglobin and bilirubin, the transferrin concentration was the same as the pool (3.26 \pm $0,01 \mathrm{~g} / 1,95 \%$ confidence limits), thus demonstrating absence of interference.

Interference from lipaemia was assessed by measuring the transferrin concentration of a grossly lipaemic serum pool before and after ultracentrifugation to remove triglyceride rich particles in a Beckman Airfuge (Beckman Instruments Incorporated, Palo Alto, CA 94304). The transferrin concentrations before and after ultracentrifugation were $3.00 \pm 0.01 \mathrm{~g} / \mathrm{l}$ and $3.08 \pm 0.01 \mathrm{~g} / 1$ respectively. The slightly lower concentration in the lipaemic sample is consistent with a dilution effect of lipid particles, as the sodium and chloride concentrations were approximately $2 \%$ lower for this sample.

Immunoturbidimetric transferrin and total iron binding capacity comparisons

It has been suggested that transferrin can be converted to total iron binding capacity using the relationship total iron binding capacity $(\mu \mathrm{mol} / \mathrm{l})=$ transferrin $(\mathrm{g} / \mathrm{l}) \times 22.75$, based on a transferrin molecular weight of 88000 and a transferrin binding capacity of $2 \mathrm{~mol}$ of iron per mol of transferrin (10).

We checked this experimentally using a total iron binding capacity method in which excess iron is re-

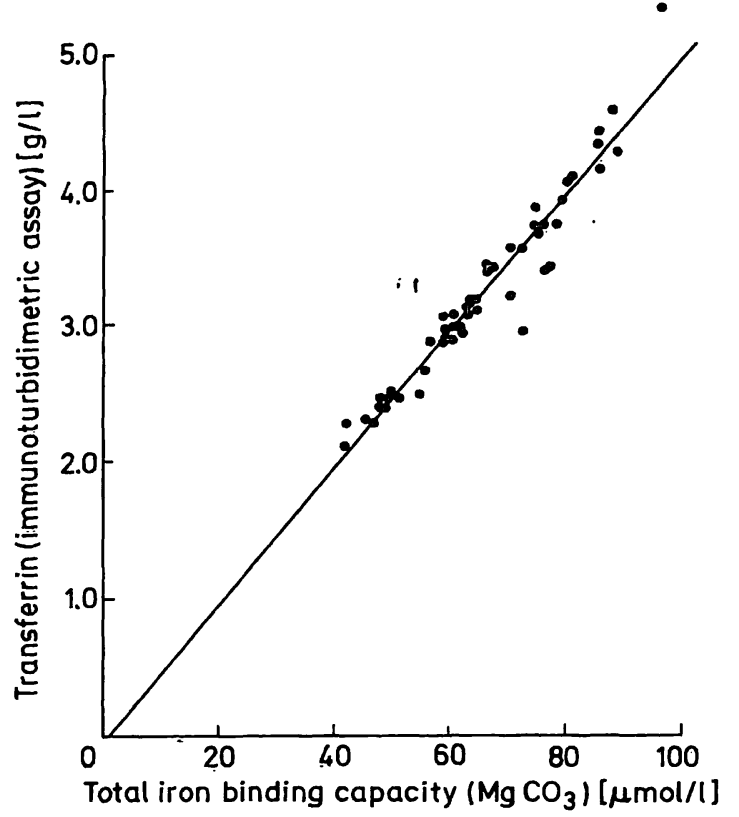

Fig. 3. Comparison of patient specimens analysed for transferrin using an immunoturbidimetric method and total iron binding capacity as described in the "Materials and Methods".

$\begin{array}{lll}\mathrm{y} \text { intercept } & = & -0.03 \\ \text { slope } & = & 0.050 \\ \mathrm{r} & = & 0.967 \\ \mathrm{n} & = & 50 \\ \mathrm{~s}_{\mathrm{y.x}} & = & 0.183\end{array}$

moved with magnesium carbonate (7). The following relationship between immunoturbidimetric transferrin $(\mathrm{g} / \mathrm{l})$ and total iron binding capacity ( $\mu \mathrm{mol} / \mathrm{l})$ was derived by assaying 50 additional patient sera:

Immunoturbidimetric transferrin $=(0.050 \times$ total iron binding capacity) $-0.030, \mathrm{r}=0,967, \mathrm{~s}_{\mathrm{y} . \mathrm{x}}=$ 0.183 . Results are shown in figure 3 .

Using the same molecular weight of 88000 for transferrin, this implies an approximate transferrin binding capacity of $1.8 \mathrm{~mol}$ of iron per mol of transferrin under the conditions used to measure total iron binding capacity in this assay. Transferrin can be converted to an approximate total iron binding capacity $(\mu \mathrm{mol} / \mathrm{l})$ by multiplying transferrin $(\mathrm{g} / \mathrm{l}) \times 20.2$. The reliability of this conversion will depend on the methods used and the contribution to total iron binding capacity of proteins other than transferrin (11).

\section{Linearity}

Linearity was assessed by making serial dilutions of a serum pool with a high transferrin concentration. Linearity was acceptable over the range of standards used to construct the non-linear calibration curve (1.0 $\rightarrow 6.0 \mathrm{~g} / \mathrm{l})$. Results above and below these limits are identified as outside the range of the assay. 


\section{Detection limit}

Detection limit was measured using the protocol recommended by the International Federation of Clinical Chemistry for assessment of analytical methods for routine use (12). At transferrin concentrations near zero, the standard deviation was 0.36 and 0.40 $\mathrm{g} / \mathrm{l}$ in two independent runs, giving a detection limit of $0.99 \mathrm{~g} / \mathrm{l}$. Thus below $1.0 \mathrm{~g} / \mathrm{l}$, absorbance changes are too small for reliable transferrin measurements, and less dilute samples or larger sample volumes should be used.

\section{Reference range}

Transferrin reference values with a mean of $3.05 \mathrm{~g} / 1$ and $95 \%$ limits from 2.45 to $3.65 \mathrm{~g} / 1$ were derived using serum from 300 apparently healthy subjects (150 males, 150 females). Data was processed by the method of Hoffman (8). A normal probability plot indicated a vèry small group of transferrin values from females in the 20 to 39 year age group and males over 60 years that did not belong to the main distribution of results (possibly due to latent iron deficiency or oestrogens).

An equivalent reference range was found for males and females $(2.45-3.65 \mathrm{~g} / 1)$. A non-parametric summary (9) of all results according to age and sex is provided in table 3 . This data should be interpreted with allowance made for the number of subjects $(n=50)$ in each group.

\section{General comments}

In routine use, the new assay is easy to perform, and 19 samples can be analysed in approximately 30 minutes. In many instances, analysis time for the same number of tọtal iron binding capacity measurements on an Auto-Analyzer (3) was more than half a day due to problems such as drifting baselines, changing sensitivity, $\mathrm{Fe}(\mathrm{OH})_{3}$ contamination of saturants, and inefficient removal of excess iron by anion exchange resins. The transferrin method is relatively inexpensive, costing approximately US $\$ 0.21$ or DM 0.48 per assay, and this could be further reduced by laboratories prepared to experiment with alternative antisera.

\section{References}

1. Penberthy, L. A. (1985) Clin. Biochem. Revs. 5, 145-1.52.

2. Itano, M. (1976) Am. J. Clin. Pathol: 66, 244-247.

3. Giovanniello, T. J., Di Benedetto, G., Palmer, D. W. \& Peters Jr., T. (1968) In: Automation in Analytical Chemistry, Technicon symposia 1967 Volume 1 (Boehm, P.S., ed.). Mediad Incorporated, New York, pp. 185-188.
Tab. 3. Data distribution (non-parametric).

\begin{tabular}{lrll}
\hline Subjects & Number & $\begin{array}{l}\text { Mean } \\
(\mathrm{g} / \mathrm{l})\end{array}$ & $\begin{array}{l}95 \% \text { Limits } \\
(\mathrm{g} / \mathrm{l})\end{array}$ \\
\hline Males & & & \\
All & 150 & 3.07 & $2.47-3.60$ \\
$20-39$ years & 50 & 3.01 & $2.40-3.49$ \\
$40-59$ years & 50 & 3.00 & $2.47-3.42$ \\
$\geqslant 60$ years & 50 & 3.22 & $2.70-4.09$ \\
Females & & & \\
All & 150 & 3.12 & $2.52-3.82$ \\
$20-39$ years & 50 & 3.23 & $2.54-4.25$ \\
$40-59$ years & 50 & 3.12 & $2.58-3.81$ \\
$\geqslant 60$ years & 50 & 2.99 & $2.50-3.61$ \\
Males and Females & 300 & 3.09 & $2.50-3.81$ \\
\hline
\end{tabular}

\section{Conclusions}

In summary, we believe that the Cobas Bio centrifugal analyser is a useful instrument for the immunoturbidimetric measurement of transferrin, provided absorbance measurements taken soon after the mixing cycle are not used for calculations. Antigen excess is not a problem in this assay (13). Initial problems may be related to small air bubbles generated in the mixing cycle in the buffered anti-transferrin reagent. We have observed that surfactant can cause falsely high absorbances immediately after the mixing cycle in conventional photometric assays (e. g. magnesium estimations using calmagite).

For routine diagnostic investigations, we now measure transferrin in place of total iron binding capacity. Although theoretical and experimental relationships can be used to convert one to the other, such conversions should be interpreted carefully due to iron binding proteins other than transferrin $(5,11)$. Most investigations concerning transferrin have been related to haematopoiesis, nutrition, infection and cell proliferation and it has recently been suggested that low levels of transferrin may prejudice the success of bone marrow transplantation and major surgery $(14,15)$. We believe that the present assay is ideal for such investigations.

4. Fudge, A. N. \& Fraser, C. G. (1978) Clin. Chem. 24, 374-376.

5. Dixon, K. (1973) Ann. Clin. Biochem. 10, 127-131.

6. Williams, H. L. \& Conrad, M. E. (1972) Clin. Chim. Acta. $37,131-140$.

7. Ramsay, W. N. M. (1957) Clin. Chim. Acta 2, 221-226. 
8. Hoffman, R. G. (1963) J. Amer. Med. Ass. 185, 864-873.

9. Solbert, H. E. (1983) J. Clin. Chem. Clin. Biochem. 21, $749-760$.

10. Boehringer Mannheim GmbH Diagnostic (1982) Insert supplied with transferrin method Cat. No. 661040.

11. Van der Heul, C., Van Eijk, H. G., Wiltink, W. F. \& Leijnse, B. (1972) Clin. Chim. Acta 38, 347-353.

12. Büttner, J., Borth, R., Boutwell, J.H., Broughton, P. M. G. \& Bowyer, R. C. (1979) Clin. Chim. Acta. 98, 145F-162F; J. Clin. Chem. Clin. Biochem. 18, 78-88 (1980).
13. Spencer, K. \& Price, C. P. (1980) In: Centrifugal Analysers in Clinical Chemistry, (Price, C. P. \& Spencer, K., eds.) Praeger Scientific, Eastbourne, pp. 457-463.

14. Hunter, R. L., Bennett, B., Garrison, C., Winton, E. F. \& Vogler, W. R. (1984) Am. J. Clin. Pathol. 81, $581-585$.

15. Hunter, R. L., Bennett, B., Towns, M. \& Vogler, W. R. (1984) Am. J. Clin. Pathol. 81, 748-753.

$$
\text { . } 1
$$

B. A. Dilena and M. J. Peakè Department of Biochemistry and Chemical Pathology Flinders Medical Centre Bedford Park

South Australia 5042

Australia 